\title{
An investigation of the impact of time of generation on carbon savings from PV systems in Great Britain.
}

\author{
P. A. Burgess ${ }^{1, *}$, M.M. Vahdati ${ }^{2}$, D. Davies ${ }^{3}$ \\ ${ }^{1}$ Technologies for Sustainable Built Environments, University of Reading, United Kingdom \\ ${ }^{2}$ School of Construction Management and Engineering, University of Reading, United Kingdom \\ ${ }^{3}$ Solarcentury, London, United Kingdom \\ * Corresponding author. Tel: +44 (0)7977 255 964, E-mail: p.a.burgess@pgr.reading.ac.uk
}

\begin{abstract}
PV only generates electricity during daylight hours and primarily generates over summer. In the UK, the carbon intensity of grid electricity is higher during the daytime and over winter. This work investigates whether the grid electricity displaced by PV is high or low carbon compared to the annual mean carbon intensity using carbon factors at higher temporal resolutions (half-hourly and daily).

UK policy for carbon reporting requires savings to be calculated using the annual mean carbon intensity of grid electricity. This work offers an insight into whether this technique is appropriate.

Using half hourly data on the generating plant supplying the grid from November 2008 to May 2010, carbon factors for grid electricity at half-hourly and daily resolution have been derived using technology specific generation emission factors.
\end{abstract}

Applying these factors to generation data from PV systems installed on schools, it is possible to assess the variation in the carbon savings from displacing grid electricity with PV generation using carbon factors with different time resolutions.

The data has been analyzed for a period of 363 to 370 days and so cannot account for inter-year variations in the relationship between PV generation and carbon intensity of the electricity grid. This analysis suggests that PV displaces more carbon intensive electricity using half-hourly carbon factors than using daily factors but less compared with annual ones.

A similar methodology could provide useful insights on other variable renewable and demand-side technologies and in other countries where PV performance and grid behavior are different.

Keywords: Renewable Energy, Photovoltaics, Carbon accounting

\section{Introduction}

The carbon intensity of grid electricity varies with the seasons and also with the time of day. Similarly the production of electricity from PV is strongly dependent on the time of year and time of day. In the case of the variation in carbon intensity of the electricity grid, this is a function of the way that overall energy demand varies and the economics of the different electricity production methods. As the UK has a diverse mix of generation technologies, the variation in carbon intensity of the grid can be quite large. At times of low demand when nuclear makes up a relatively large proportion of the active generating plant, the carbon intensity tends to be relatively low; at times of the highest demand, the grid has all available nuclear and renewable power and a roughly equal mix of coal and gas supplying the remaining demand, leading to an intermediate carbon intensity figure. The times of highest carbon intensity occur when there is moderate to high demand and the cost of producing electricity from coal is lower than the cost of producing electricity using gas.

In the UK, company carbon reporting of the energy exported from microgeneration must be reported using the annual grid average carbon emissions factor [1] which may not be truly reflective of the grid mix at the time of generation. 
This paper seeks to determine the relationship between the variation of the carbon intensity of the mixture of sources feeding the grid and the variation in the time of PV.

\section{Methodology}

There are three sources of data that or central to this work. Firstly, the half-hourly generation by fuel type data for the UK national grid [2]. This provides gross electricity production from eleven sources (including interconnectors and pumped storage hydro) for Great Britain. Data has been collated from November 2008 to June 2010. These figures do not make any allowance for parasitic loads within power stations which are considered in the second set of data, the average emissions factor for each fuel type in the half hourly generation by fuel type data. These generation emission factors (GEFs) are taken from AMEE [3] based on data in DUKES [4]. The GEFs provided by AMEE are for gross generation with a generated to supplied gross factor to allow for conversion from carbon intensity of gross electricity generation to the carbon intensity of the electricity fed into the grid. To convert these from grid supplied factors to the carbon intensity of electricity at the point of use, the losses in transmission and distribution (T\&D) must be considered. We have used a flat figure for T\&D losses of $9 \%$ [5].

Table 1 End use $\mathrm{CO}_{2}$ emissions factors for each generation technology.

\begin{tabular}{ccccc}
\hline Fuel Type & $\begin{array}{c}\text { Generated To } \\
\text { Supplied } \\
\text { Gross Factor }\end{array}$ & $\begin{array}{c}\text { Mass } \mathrm{CO}_{2} \\
\text { Produced per } \\
\text { Energy Unit } \\
(\mathrm{kg} / \mathrm{kWh})\end{array}$ & $\begin{array}{c}\text { Derived Supplied } \\
\text { Net Factor } \\
(\mathrm{kg} / \mathrm{kWh})\end{array}$ & $\begin{array}{c}\text { Derived End-use } \\
\text { Factor allowing } \\
\text { for T\&D losses }\end{array}$ \\
\hline CCGT & 0.984 & 0.385 & 0.391 & 0.430 \\
Coal & 0.949 & 0.861 & 0.907 & 0.997 \\
INTFR & 1 & 0.082 & 0.082 & 0.090 \\
INTIRL & 1 & 0.549 & 0.549 & 0.603 \\
NPSHYD & 0.997 & 0 & 0 & 0 \\
Nuclear & 0.908 & 0 & 0 & 0 \\
OCGT & 0.944 & 0.525 & 0.556 & 0.611 \\
Oil & 0.828 & 0.737 & 0.889 & 0.977 \\
Other & 1 & 0 & 0 & 0 \\
PS & 0.997 & 0 & 0 & 0 \\
Wind & 1 & 0 & 0 & 0 \\
\hline
\end{tabular}

Applying the resulting end-use GEFs (Table 1) to the generation by fuel type data gives the total $\mathrm{CO}_{2}$ emissions from each fuel type for every half hour. Once this is completed, the task of deriving grid mix carbon intensity for any given time frame is achieved by dividing the total carbon emissions over the time by the electricity generated over that time. For this work, the time intervals considered are half hourly, daily and total period which varies slightly from system to system but all start between the $13^{\text {th }}$ and $26^{\text {th }}$ May 2009 and all run for between 363 and 370 days and can be thought of as an annual grid average carbon factor.

No account has been made for non- $\mathrm{CO}_{2}$ GHG emissions from generation, for upstream emissions, for the embodied emissions associated with the generation infrastructure or end-of life disposal. The official methodology published by the UK Government [1] has only recently started including non- $\mathrm{CO}_{2}$ GHGs in their electricity factors and these were not included for simplicity. The remaining omissions from this study are categories that are not consistent with the GHG reporting guidelines prevalent in the UK at the time of writing. 
The final dataset used for this work was the generation from seven PV systems in the North of England provided by Solarcentury. All systems are $4 \mathrm{~kW}_{\mathrm{p}}$ crystalline silicon systems oriented due south with a tilt of $30^{\circ}$. All data was for a period from a point in May 2009 to a point in May 2010 in 15-minute time steps. These were converted to half-hourly generation data.

In 32 half hourly periods across the generation by fuel type dataset only interconnector data had been recorded. In this study these half hours have been excluded from the analysis.

The carbon savings from PV generation were calculated using half hourly, daily and overall period emissions factors and the results compared.

All calculations were done using MS Excel 2007.

\section{Results}

The analysis of the variation in time of generation and carbon intensity of the grid presented in this section gives a clear indication of the main findings of the study. For systems with a similar generation profile, the differences between carbon savings from the annual average and from half-hourly carbon emissions factors are very similar.

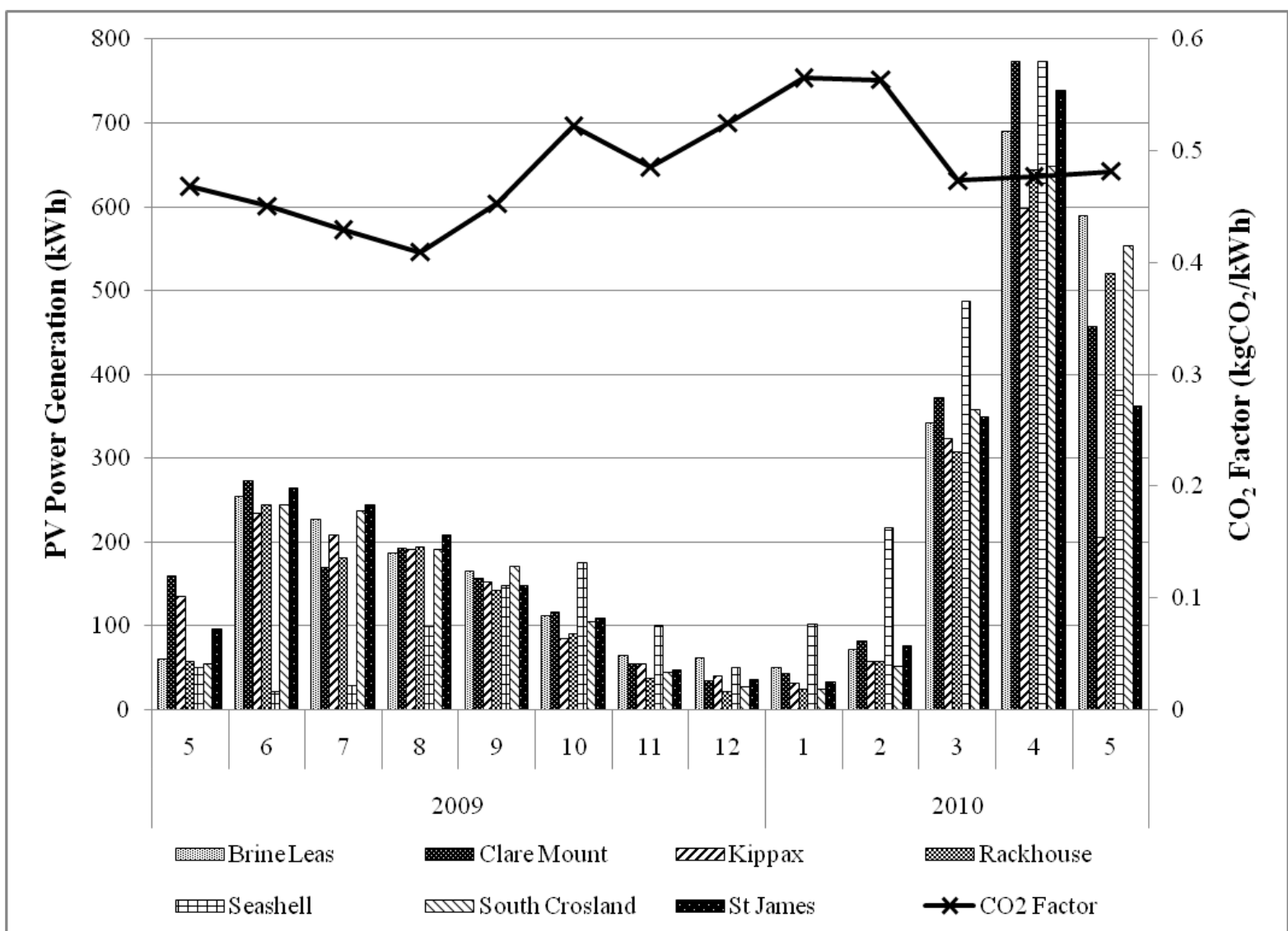

Figure 1 Monthly generation by each system $(\mathrm{kWh})$ and Monthly average grid mix $\mathrm{CO}_{2}$ emissions factor

Figure 1 shows a similar generation profile for all seven systems over the monitoring period with the exception of Seashell which has significantly lower generation in 2009 relative to the other systems. In all cases the generation in March to May 2010 is significantly higher than summer 2009 indicating that conditions for solar generation were more favorable in 2010 than 2009. 
Figure 1 also gives a clear indication of the seasonal variation in $\mathrm{CO}_{2}$ intensity with the highest monthly emissions factors being over the winter months (note the graph shows a year from May to May so winter is in the middle).

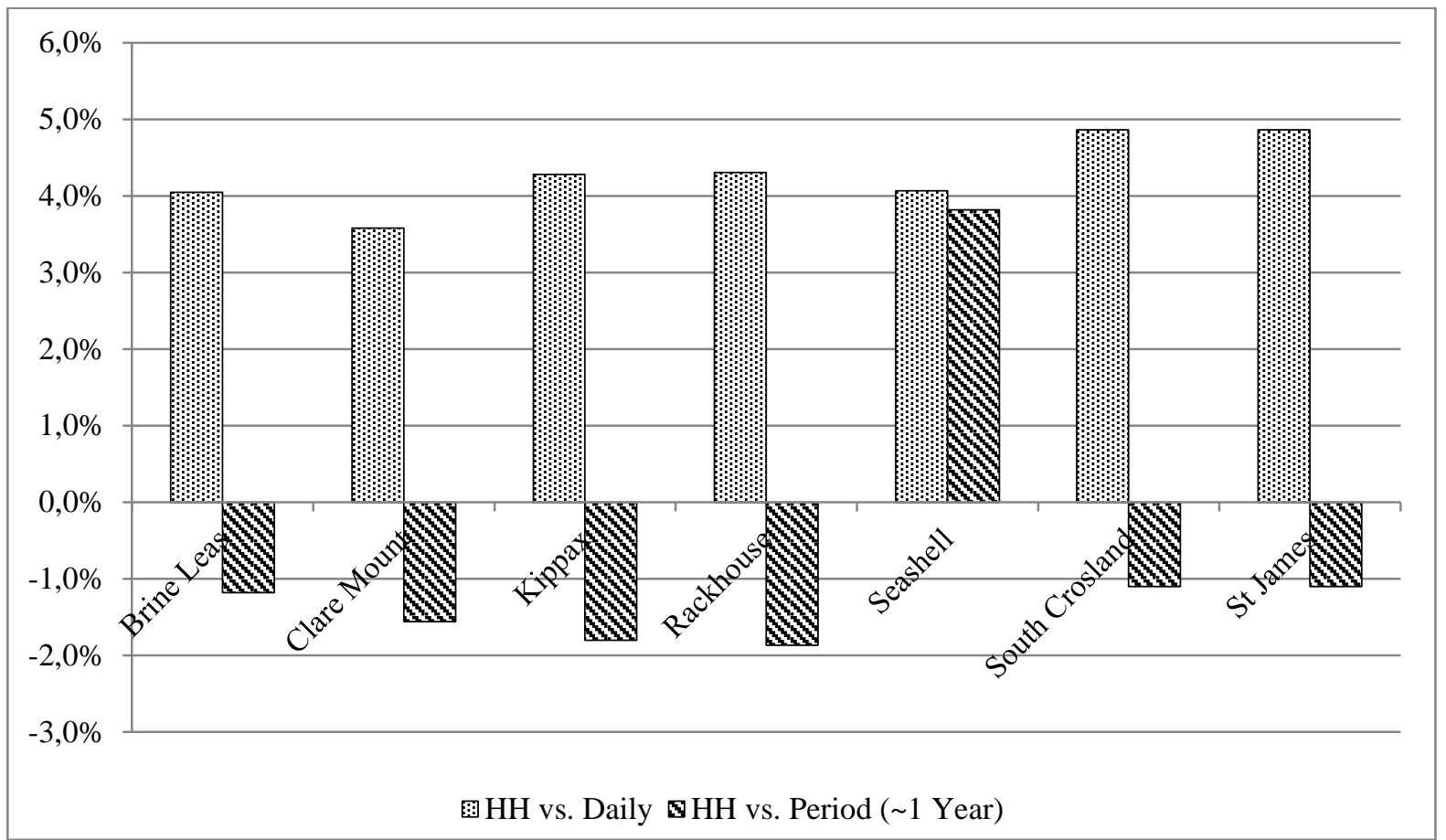

Figure 2 The difference between carbon savings using carbon factors with different time resolutions.

Figure 2 shows a clear trend across six of the seven systems analyzed with $\mathrm{CO}_{2}$ savings assessed using half hourly emissions factors for the time of generation outperforming the average daily factor for the day of generation by between 3.5 and 5 percent. Comparing the half hourly performance against the period average grid mix emissions factor, carbon savings were 1 to 2 percent lower using the half hourly emissions factors. The clear exception to this is the comparison between the period average and half hourly figure for Seashell. This is likely to be a consequence of the different pattern of generation for Seashell seen in Figure 1 with a much smaller proportion of the system's generation in 2009 than in the other six cases. 


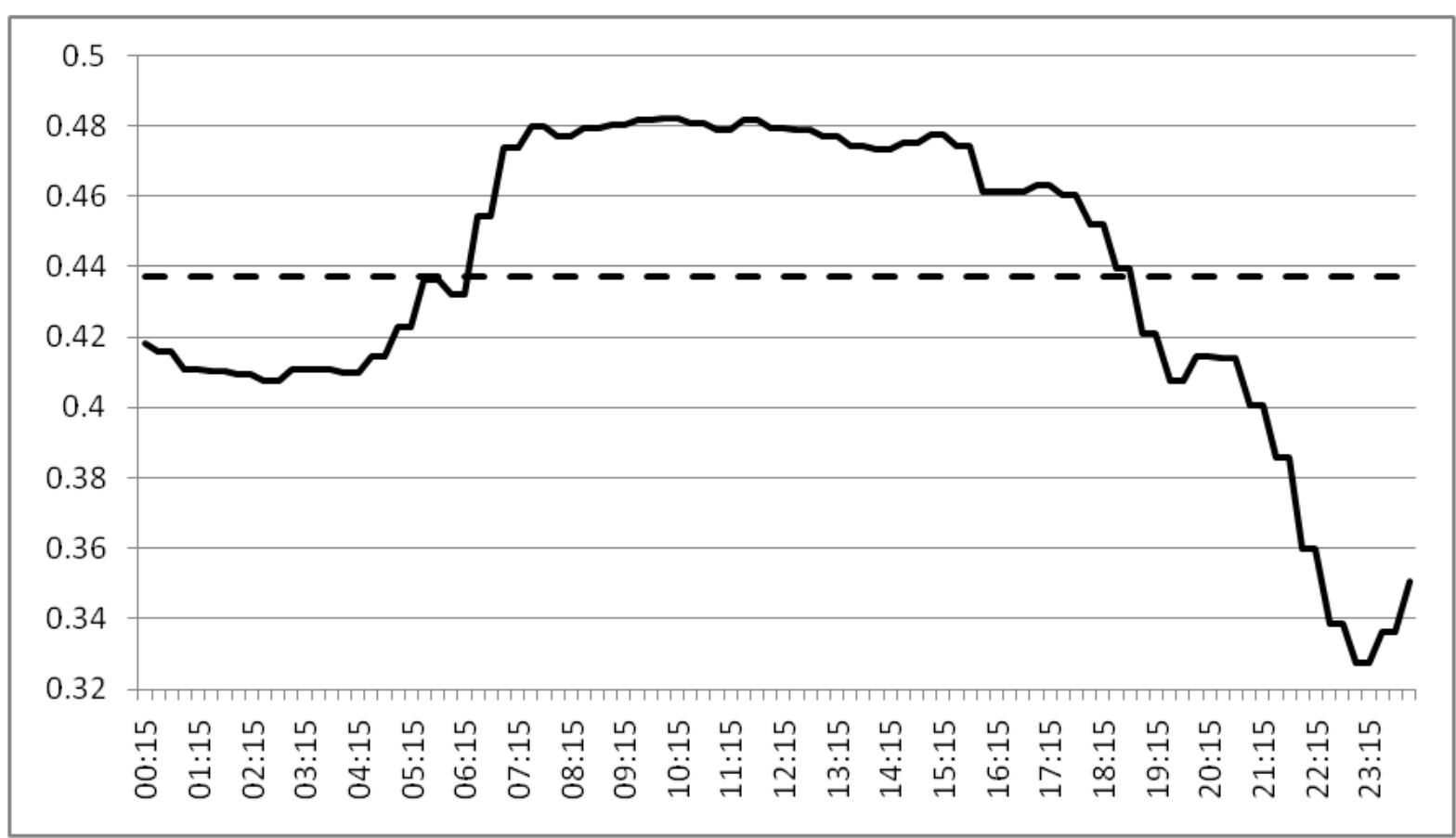

Figure $3 \mathrm{CO}_{2}$ factor variation for 17 July 2009 (typical summer day). Solid line is half hourly variation, dashed line is daily average.

The difference in carbon savings between half hourly and daily emissions factors can be easily understood by observing figure 3 which shows the variation in grid $\mathrm{CO}_{2}$ for a typical summer's day. The profile is essentially a step function with lower carbon generation overnight and higher carbon generation over the daytime when PV will be generating. The typical winter profile is similar but with a still higher level in the evening corresponding to high demand for electricity for lighting, electric heating etc.

\section{Discussion and Conclusions}

\subsection{Previous work}

Previous studies have considered the carbon intensity of grid energy as it relates to PV generation for the purpose of life cycle analysis [6],[7] however these typically model emissions the typical conditions for an 'average' year rather than real data used for a historical analysis as in this work. Studies have also modeled the impact of PV at times of peak demand [8] but not the type of full year, short time-step analysis presented in this paper; the average relationship between time of generation and marginal emissions of $\mathrm{CO}_{2}$ [9] and evaluated marginal emissions factors over a number of years [10].

Molin et al. [11] presented a study on the financial impacts of net metering for PV based on variable time intervals; hourly, monthly and yearly. This study suggested that net metering is most beneficial for PV using a full year for the time interval. This held true when assessed against data for Sweden, Germany and Spain using a 13-year long dataset. There are interesting parallels between this work which deals with financial performance at different time steps and our work which deals with carbon accounting at different time-steps. The key result of this study which applies to our own work is the suggestion that year-to year variation is relatively modest. It also highlights that an international version of our study would be of great value, particularly as the grid carbon intensity profile can be very different from country to country. As a caveat to this point, electricity markets where a single fuel dominates such as 
France (nuclear) and hence only have limited variation in carbon intensity, a repeat of our study would not be worthwhile.

This work has as its basis the variation in average grid mix emissions factor on a half hourly basis without any consideration of inter-year variability. The aim of this work was to assess the validity of using annual average grid mix electricity emissions factors for calculating the carbon savings resulting from exported renewable microgeneration. Current company carbon reporting guidelines use overall grid mix carbon factors rather than marginal factors (which on the existing UK grid will almost always be higher than the average grid mix) on the basis that all consumers have a shared responsibility for electricity emissions rather than different consumers taking electricity from different sources, this work maintains this philosophy of shared responsibility at any given time but with variability introduced depending on the time of PV generation. The authors consider that there is merit to the use of a time-varying emissions factor as an incentive to businesses to engage in more active demand-side management, Gyamfi et al [12] found that the reduction of $\mathrm{CO}_{2}$ emissions would be as significant motivation for consumers to initiate demand side management as price signals and second only to avoiding blackouts.

\subsection{Sources of error}

The results of this work are based on PV generation for a single year. As can be seen from the clear difference between the results for Seashell and for the other six systems, PV generation data gathered over a longer timescale would allow for more authoritative findings. It is clear that for systems with similar generation profiles, the resulting carbon savings are closely related.

The gaps in the half hourly generation by fuel type tables were explicitly omitted from the remainder of the study on the basis that they accounted for an extremely small proportion of the dataset. A more thorough treatment would entail the generation of synthetic data to fill these gaps based on a logical process which may include some combination of activity either side of the data gaps, prevailing conditions and additional datasets such as those for overall electricity demand.

The emissions factors for the grid used in this study are exclusively for direct carbon emissions from electricity generation and do not take account of any emissions upstream of the power station. Including these indirect emissions would result in a truer picture of the emissions associated with electricity generation at the cost of increased uncertainty about the exact level of GEFs depending on which indirect emissions are included and the assumptions made when calculating indirect emissions.

\subsection{Simplifications and assumptions}

In this study, PV generation is treated as a negative load on the grid. In Great Britain where there is only a small amount of PV on the grid, this approach is adequate however with a significant amount of PV generation on the grid the low carbon electricity produced by PV will be rolled into the overall grid mix emissions factor. In this scenario, a negative demand approach would lead to double counting of the carbon emissions reductions from PV.

\subsection{Future \& applications}

The results of this work clearly show that for PV, the carbon emissions saved by the renewable electricity generated are different from that which is estimated using the annual average grid mix emissions factor. If similar work for other technologies including other 
renewables and energy efficiency technologies which have a time-varying behavior can also be shown to differ from the annual average grid mix emissions factor, there may be a case for altering the reliance on the annual average for company reporting of carbon emissions. With the arrival of improved metering technology allowing for measurement of electricity use at high time resolution, this kind of temporally sensitive reporting would become genuinely feasible.

This study has shown that carbon savings from PV appear to be lower based on emissions factors for the time of generation than with annual average emissions factors in Great Britain where the grid is higher in carbon over the winter where demand peaks. The situation may well be reversed in a region where peak electricity demand and carbon intensity are over summer as a result of cooling loads.

The authors intend to develop a system for including real time carbon savings in PV system monitoring. The study presented here will be widened to cover a larger number of PV systems and a longer timeframe, given the similarity of the results across PV systems it may be possible to reliably estimate the percentage difference between half hourly and annual emissions factors for systems where this kind of analysis is not undertaken. An investigation of how real time carbon savings against marginal grid carbon emissions can be reliably calculated may also prove to be a valuable exercise.

\section{Acknowledgements}

The authors would like to thank the EPSRC for funding this work.

\section{References}

[1] DEFRA, Guidance on how to measure and report your greenhouse gas emissions, 2009, pp. $49-53$

[2] Elexon Portal, Historic Generation By Fuel Type Data Files, https://elexonexchange.bsccentralservices.com/page_object_view.php?uid=76, Accessed online August 2010 (login required)

[3] AMEE, Fuel Emission Factors, http://explorer.amee.com/categories/Electricity_Generation_Emission_Factors/data, accessed online August 2010 (login required)

[4] DECC, Digest of United Kingdom Energy Statistics, 2009

[5] DTI, Future Network Technologies, 2006, pp. 4-5

[6] S. Krauter, Greenhouse Gas Reduction by PV, Proceedings of $3^{\text {rd }}$ World Conference on Photovoltaic Energy Conversion, 2003, pp. 2610 - 2613

[7] R. Laleman et al, Life Cycle Analysis to estimate the environmental impact of residential photovoltaic systems in regions with a low solar irradiation, Renewable and Sustainable Energy Reviews Vol 15, 2011, pp. 267-281

[8] R. Spiegel et al, Demonstration of the Environmental and Demand-Side Management Benefits of Grid-Connected Photovoltaic Power Systems, Solar Energy Vol. 62, No. 5, 1998, pp. 345-358

[9] G. Keolian and G. Lewis, Modeling the life cycle energy and environmental performance of amorphous silicon BIPV roofing in the US, Renewable Energy 28, 2003, pp. 271-293 
[10]A.D. Hawkes, Estimating marginal $\mathrm{CO}_{2}$ emissions rates for national electricity systems, Energy Policy 38, 2010, pp. 5977-5987

[11]A. Molin et al, Positive power market value for grid-connected roof-top solar power in Sweden, in Proceedings of the $11^{\text {th }}$ World Renewable Energy Congress (WREC XI), Abu Dhabi, UAE, 25-30 September 2010

[12]S. Gyamfi et al. Demand Response in the Residential Sector: A Critical Feature of Sustainable Electricity Supply in New Zealand, $3^{\text {rd }}$ International Conference on Sustainability Engineering and Science, Auckland, NZ, 2008 